\title{
ANALISIS BILANGAN RICHARDSON (Ri) UNTUK STABILITAS ATMOSFER METEOROLOGI MIKRO DI STAKLIM BOGOR
}

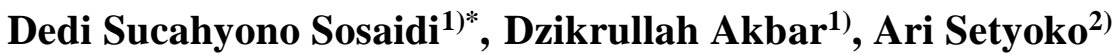 \\ 1) Sekolah Tinggi Meteorologi Klimatologi dan Geofisika, Jalan Perhubungan I No.5 Pondok Betung, \\ Bintaro, Kec. Pd. Aren, Kota Tangerang Selatan, Banten 15221 \\ *den_dei@yahoo.com \\ 2) Stasiun Klimatologi Bogor, Jl. Tambakan, RT.01/RW.04, Situgede, Kec. Bogor Bar., Kota Bogor, Jawa \\ Barat 16116
}

\begin{abstract}
Micro-scale meteorology $\alpha$ is a meteorology whose time is $<1$ hour and the radius range is $<2 \mathrm{~km}$. This research in Bogor Climate Station calculates micro scale stability with Richardson Numbers $(R i)$ which is able to classify the stability and convection process, by calculating dynamic stability based on wind and temperature data at 4 meters, 7 meters and 10 meters for April 1st until-10th 2019 The results of the analysis of the value of Ri numbers, with 30 observations for condition 1 according to Stull (1988) conditions 20 times neutral, 8 times unstable, and 2 times stable. As for condition 2, free convection occurs 14 times, forced convection 10 times, and neutral 6 times. During the 30 observation periods, 9 times of rain occurred with 3 times of free convection, 3 times of forced convection, and 1 time of neutral events.
\end{abstract}

Keywords: Micro-scale meteorology, Richardson number (Ri), forced convection, free convection.

\begin{abstract}
ABSTRAK
Meteorologi skala mikro $\alpha$ adalah meteorologi yang kejadian waktunya $<1$ jam dengan wilayah jangkauan radiusnya $<2 \mathrm{~km}$. Penelitian di Staklim Bogor ini menghitung stabillitas skala mikro dengan Bilangan Richardson (Ri) yang mampu mengklasifikasikan stabilitas dan proses konveksi, dengan menghitung stabilitas dinamis berdasarkan data angin dan suhu pada level 4 meter, 7 meter, dan 10 meter untuk tanggal 1 - 10 April 2019. Hasil analisis dari nilai bilangan Ri, dengan 30 kali pengamatan untuk kondisi 1 menurut Stull (1988), terjadi kondisi netral 20 kali, 8 kali unstabil, dan 2 kali stabil. Sedangkan untuk kondisi 2, terjadi konveksi bebas 14 kali, konveksi paksa 10 kali, dan netral 6 kali. Selama 30 periode pengamatan terjadi hujan 9 kali kejadian dengan masa konveksi bebas 3 kali, konveksi paksa 3 kali, dan saat kejadian netral 1 kali.

Kata kunci: Meteorologi skala mikro, bilangan Richardson (Ri), konveksi paksa, konveksi bebas.
\end{abstract}

\section{PENDAHULUAN}

Seperti kita ketahui akitivitas meteorologi mikro juga sangat diperlukan untuk keperluan analisis pada ruang yang sempit dan waktu yang singkat, dengan skala jarak radius maksimum 1 hingga 2 km dengan waktu kurang 1 jam. Untuk kejadian meteorologi kurang dari 1 menit dan dalam radius jarak < $20 \mathrm{~m}$, seperti kejadian turbulensi dapat disebut sebagai kejadian meteorologi mikro yang paling kecil. Menurut Orlanski (1975), 
skala ini dikenal dengan skala $\gamma$. Sedangkan jika kejadian meteorologinya waktunya lebih dari 1 menit dan kurang dari setengah jam atau 30 menit maka dapat dikategorikan sebagai meteorology skala $\beta$, dan fenomena yang terjadi dapat berupa seperti dust devil thermal (lisus, pusaran udara kering yang beterbangan), atau tornado skala kecil. Jika kejadian meteorologinya hingga radius $<2 \mathrm{~km}$, dengan waktu $<1$ jam, dikenal sebagai meteorologi mikro skala $\alpha$. Fenomena yang dapat dijumpai adalah seperti Large Tornados (Tornado), short gravity waves (contoh gelombang gunung). Menurut Fujita (1981) skala $\gamma$ dikenal dengan miso $\alpha$ scale, skala $\beta$ dikenal dengan miso $\beta$ scale, dan skala $\alpha$ dikenal dengan miso $\alpha$ scale.

Meteorologi mikro sendiri merupakan ilmu yang mempelajari fenomena yang terjadi pada lapisan udara paling dekat permukaan (Sutton, 1953; Arya 2001). Salah satu unsur meteorologi yang dampaknya mempengaruhi keadaan sekelilingnya adalah angin dan curah hujan. Peran angin adalah sebagai pembawa massa udara. Massa udara yang mengalir akan melewati kekasaran permukaan dan terjadilah transfer momentum. Massa udara akan diserap oleh permukaan, sehingga terjadi tahanan permukaan yang menjadikan kecepatan angin semakin bawah semakin berkurang. Oleh karenanya untuk mengetahui aliran massa udara diukurnya parameter meteorologi mikro dalam beberapa level, yaitu level 4 meter, 7 meter, dan 10 meter.

Selain angin, unsur meteorologi lainnya adalah suhu. Dengan data angin dan suhu pada berbagai lapisan tersebut maka akan diperoleh nilai stabilitas dinamis. Bilangan Richardson (Ri) adalah parameter yang dapat mengukur stabilitas atmosfer dan kondisi turbulensi lokal (Ashafi and Hoshyaripour, 2010). Faktor ini juga ditemukan untuk menjadi dasar dalam penyeberan dan transport polutan secara lokal dan skala regional (Stull, 1988). Alisawati (2019) dalam penelitian di Banjarbaru Kalimatan Selatan, mendapatkan korelasi antara Bilangan Richardson (Ri) dengan transfer bahang dan momentum pada periode JJA (Juni, Juli, Agustus 2019) mendapatkan nilai korelasi (r) antara 0.41 hingga 0.68 pada ketinggian 4 meter.

Di sisi lain transfer bahang dan momentum sangat berkaitan dengan stabilitas atmosfer. Hal tersebut diteliti oleh Haidar (2019) dalam penelitiannya di Tangerang Selatan, menghitung kondisi stabilitas permukaan dengan nilai Ri sebelum kejadian hujan cenderung negatif, sedangkan saat hujan Ri positif, dan setelah kejadian hujan Ri cenderung nol (0). Penelitian ini akan mengkaji stabilitas mikro atau stabilitas udara 
hubungannya dengan hujan dan juga proses fisis di atmosfer yaitu proses konvektivitas dalam lingkup mikro di Stasiun Klimatologi Kelas I Bogor.

\section{METODOLOGI}

Curah hujan atau endapan adalah air yang jatuh dari awan ke bum. Hujan diukur dengan penakar hujan konvensional atau yang sering disebut ombrometer, ada yang manual dan otomatis. Satuan curah hujan biasanya dinyatakan dalam millimeter ( $\mathrm{mm})$. (Sucahyono,D dan Ribudiyanto,K, 2013). Penaksiran analisis terjadinya hujan jika berkaitan dengan indikator intensitas per waktu $(\delta \mathrm{I} / \delta \mathrm{T})$, karena adanya energy yang yang berhubungan dengan perubahan panas/suhu.Dan jika ditinjau dari aliran maka keadaan tersebut berhubungan dengan angin. Untuk pertukaran sifat hujan berkaitan dengan awan. Jika indikator hujan ditinjau dari jumlahnya (R), penaksiran dari aspek energi berkaitan dengan perubahan suhu juga. Dan dari aspek aliran jumlah curah hujan berhubungan juga dengan angin. Namun dari sisi aspek pertukaran sifat, jumlah curah hujan berhubungan dengan kemantapan/stabilitas udara.(Wiryohamijoyo.S \& Swarinoto.Y.S, 2013). Secara umum ada tiga jenis curah hujan yang terjadi di wilayah Indonesia (tropis), yaitu konveksional, siklonik, dan orografik.

Tabel 1 Keadaan hujan dan intensitas hujan (Suyono, 1985)

\begin{tabular}{crcc}
\hline \multirow{2}{*}{ No } & Keadaan Hujan & \multicolumn{2}{c}{ Intensitas Hujan $(\mathrm{mm})$} \\
\cline { 3 - 4 } & & 1 Jam & 24 Jam \\
\hline 1 & Hujan sangat ringan & $<1$ & $<5$ \\
2 & Hujan ringan & $1-5$ & $5-20$ \\
3 & Hujan normal & $5-10$ & $20-50$ \\
4 & Hujan lebat & $10-20$ & $50-100$ \\
5 & Hujan sangat lebat & $>20$ & $>100$ \\
\hline
\end{tabular}

Curah hujan konveksional disebabkan oleh konveksi bebas akibat pemanasan, proses dinamik seperti konvergensi atau pemaksaan fisis di atas pegunungan.(Wiryohamijoyo.S \& Swarinoto.Y.S, 2013). Curah hujan konveksional bisa terjadi dalam ruang $10-20 \mathrm{~km}$ persegi. Untuk hujan orografik disebabkan oleh kondensasi dan pembentukan awan udara 
lembab yang dipaksa naik oleh gunung atau barisan pegunungan. Jadi hujan orografik dapat dikategorikan sebagai adanya konveksi paksa.

Penelitian tentang kondisi stabilitas atmosfer dengan bilangan Richardson telah dilakukan juga oleh V. Tricio dkk pada Februari 1999, di Villafria Airport dekat kota Burgos wilayah Castillay Leon Spanyol. Hasil penelitannya medapatkan dengan formulasi bilangan Richardson (Ri) menunjukkan bahwa dalam kondisi netral dan stabil dominan dalam data yang dianalisis; formulasi geometris menyebabkan beberapa hasil yang berbeda, dengan situasi jumlah yang lebih besar, diikuti oleh stratifikasi paksa yang tidak stabil dan netral di musim dingin. Penelitian tersebut juga mendapatkan formasi dari Kelvin-Helmholtz dan terlepas dari pengurangan jumlah kasus, dimungkinkan untuk menunjukkan bahwa proses mekanik melebihi kondisi daya apung. Akhir dari penelitian tersebut menunjukkan perbedaan matematika antara berbagai $\mathrm{Ri}$, formulasi dalam kontribusi termal dan dinamis untuk variasi dalam data meteorologi yang digunakan.

Stabilitas atmosfer dapat ditentukan dengan metode statis dan dinamis. Penentuan keadaan stabilitas atmosfer statis dihitung dari gradien suhu, sementara itu untuk stabilitas atmosfer dinamis perhitungannya ditentukan oleh gradien suhu dan angin. Keadaan stabilitas atmosfer dinamis digambarkan dengan Bilangan Richardson (Ri).

Bilangan Richardson merupakan salah satu metode yang digunakan untuk menentukan kategori kestabilan atmosfer (Oke, 1988). Ri menggunakan perubahan suhu dan kecepatan angin terhadap ketinggian dalam melakukan perhitungannya. Perhitungan ini memiliki keterbatasan diantaranya jika ada kesamaan dalam koefisien yang digunakan dalam perhitungan. Bilangan Ri dirumuskan sebagai berikut (Oke, 1988):

$$
\mathrm{Ri}=\frac{g}{T_{\mathrm{a}}} \frac{\left(\frac{\partial \theta}{\partial z}\right)}{\left(\frac{\partial u}{\partial z}\right)^{2}}
$$

Keterangan :

g : Kecepatan gravitasi $\left(\mathrm{m} / \mathrm{s}^{2}\right)$

$\theta \quad:$ Suhu potensial (K)

$\mathrm{T}_{\mathrm{a}} \quad$ : Suhu absolut pada ketinggian $\mathrm{z}_{\mathrm{a}}: \mathrm{z}_{\mathrm{a}}=\left(\mathrm{z}_{1} \mathrm{z}_{2}\right)^{1 / 2}$

$\mathrm{u} \quad$ : Kecepatan angin $\left(\mathrm{m} \mathrm{s}^{-1}\right)$

z $\quad$ : Tinggi Pengukuran (m) 
Suhu potensial lingkungan dapat di cari dengan menggunakan persamaan sebagai berikut (Oke, 1988):

$$
\theta=T-(\Gamma \mathrm{d} . z)
$$

Keterangan :

$\mathrm{T} \quad$ : Suhu Lingkungan (K)

$\Gamma_{\mathrm{d}} \quad$ : Dry Adiabatic Lapse Rate atau penurunan suhu pada adiabatik kering

$$
=-0.00976 \mathrm{~K} / \mathrm{m}
$$

$\mathrm{z} \quad$ : Tinggi Pengukuran (m)

Kecepatan angin rata-rata pada ketinggian z diperoleh melalui persamaan sebagai berikut:

$$
\frac{u(z)}{u^{*}}=\frac{1}{k} \ln \frac{(z-d)}{z_{0}}
$$

Keterangan :

$\mathrm{u}(\mathrm{z})$ : kecepatan angin rata-rata pada ketinggian $\mathrm{z}(\mathrm{m} /$ detik$)$

$\mathrm{u}^{*} \quad$ : kecepatan kasap (m/detik)

k : : konstanta Von Karman 0.4

$\mathrm{z}_{\mathrm{o}} \quad$ : panjang kekasapan $(\mathrm{m})$

d : perpindahan bidang nol $(\mathrm{m})$

Pada umumnya kecepatan angin rata-rata $\mathrm{u}(\mathrm{z})$ naik secara linier terhadap $\ln (\mathrm{z}-\mathrm{d})$. Nilai $\mathrm{d}$ ini berkisar antara 0.6 sampai $0.8 \mathrm{~h}(\mathrm{~h}=$ tinggi unsur kekasapan). Nilai d dapat diduga dengan persamaan berikut (Oke, 1978; Suciatiningsih, 2013, Haidar, 2019):

$$
d=\frac{2}{3} h
$$

h merupakan tinggi rata-rata permukaan (m). Untuk h di Staklim Bogor diasumsikan 4 meter

Nilai parameter $\mathrm{z}_{0}$ ditentukan dengan mengekstrapolasi hubungan linier antara $\mathrm{u}(\mathrm{z})$ dan $\ln (\mathrm{z}-\mathrm{d})=\mathrm{z}_{0}\left(\mathrm{y}=\ln \mathrm{z}_{0}\right)$, dan menghasilkan slope $=\mathrm{k} / \mathrm{u}^{*}$.

Menurut Oke (1988), nilai $\mathrm{z}_{0}$ dapat ditentukan dengan persamaan sebagai berikut:

$$
\log z_{0}=\log h-0,98
$$

Karakteristik nilai parameter $z_{0}$ dan $d$ berubah-ubah secara sistematis mengikuti perubahan angin. Pada beberapa permukaan, nilai $\mathrm{z}_{0}$ turun seiring dengan menurunnya keceatan angin dan $\mathrm{d}$ hampir konstan. Namun diatas permukaan yang lain, $\mathrm{z}_{0}$ naik dengan meningkatnya kecepatan angin dan d turun. 
Tabel 2 Kriteria Untuk Kestabilan Atmosfer (Stull, 1988)

\begin{tabular}{ccc}
\hline Kondisi & Kriteria & Klasifikasi Atmosfer \\
\hline \multirow{2}{*}{1} & $\mathrm{Ri}=0$ & Netral \\
& $\mathrm{Ri}<0$ & Unstabil \\
& $\mathrm{Ri}>0$ & Stabil \\
\hline & $\mathrm{Ri}<-0.03$ & Konveksi bebas \\
2 & $\mathrm{Ri}>-0.03$ & Konveksi Paksa \\
& $\mathrm{Ri}>0.25$ & Stabil \\
& $\mathrm{Ri}=0$ & Netral \\
\hline
\end{tabular}

Data yang digunakan dalam penelitian ini adalah data meteorologi mikro berupa data angin dan suhu pada lapisan 4 meter, 7 meter, dan 10 meter, juga curah hujan per jam diperoleh dari grafik intensitas per jam pias curah hujan tipe hujan otomatis dari pias Helman. Untuk periode data yang diolah adalah hasil pengamatan jam 07.00, 13.00, 18.00 waktu setempat (local time),selama tanggal 1 hingga 10 April 2019.

\section{PEMBAHASAN}

Berdasarkan hasil perhitungan stabilitas atmosfer meteorologi mikro di Stasiun Klimatologi Kelas I Bogor selama periode tanggal 1 sampai dengan 10 April 2019 diperoleh klasifikasi seperti dalam Tabel 2 yang menggambarkan kondisi 1 untuk kriteria kestabilan atmosfer (Stull, 1988) setelah perhitungan. Sepanjang 30 pengamatan kondisi atmosfer didominasi keadaan netral sebanyak 20 kejadian, kondisi stabil 2 kejadian dan unstabil 8 kejadian.

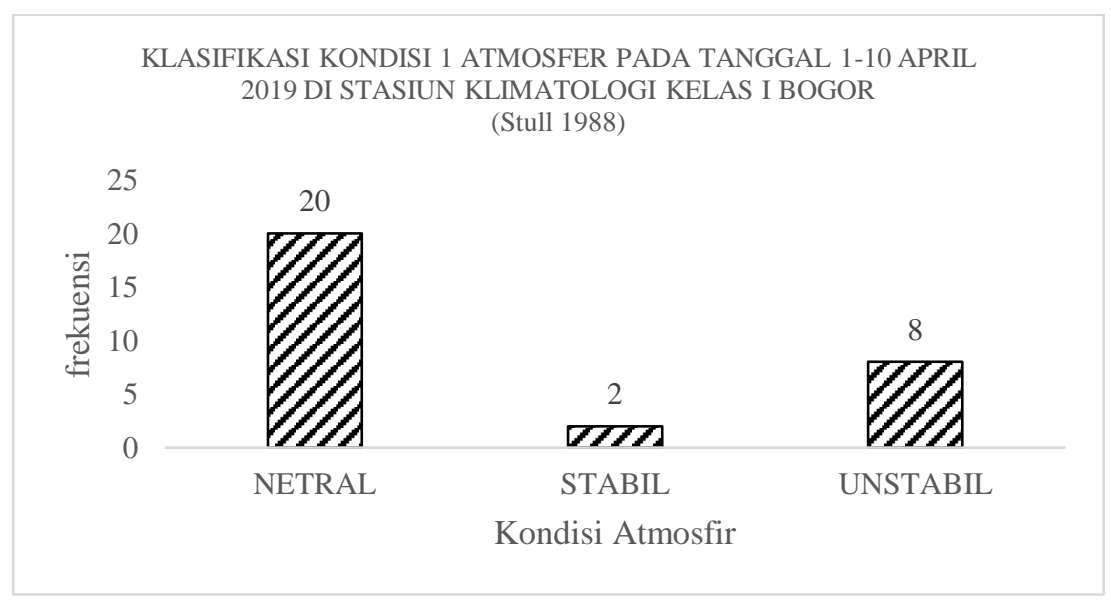

Gambar 1 Frekuensi kondisi atmosfer di Stasiun Klimatologi Kelas I Bogor selama penelitian 
Kondisi netral umumnya terjadi ketika intensitas matahari kecil, yaitu pada saat pagi hari, saat aktivitas matahari baru mulai, begitu juga saat matahari mulai terbenam. Hanya sedikit saja kondisi netral terjadi pada tengah hari. Sedangkan pada saat tengah hari kondisi atmosfer lebih didominasi oleh kondisi unstabil. Kondisi stabil umumnya terjadi saat hujan dengan intesitas ringan atau setelah hujan.

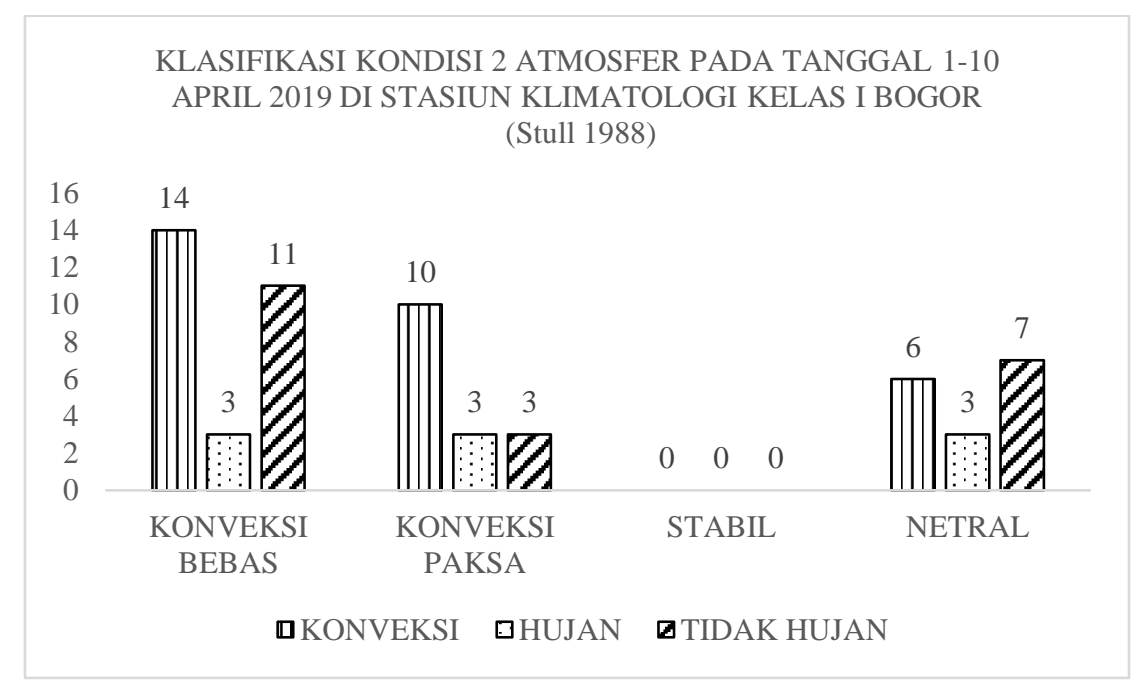

Gambar 2 Frekuensi konveksi dengan kondisi hujan di Stasiun Klimatologi Kelas I

Bogor selama penelitian

Untuk kondisi 2 yang menggambarkan klasifikasi atmosfer bebas dan konveksi paksa serta kejadian hujan dan tidak hujan tertera dalam grafik Gambar 1. Hasil tersebut menunjukkan proses konveksi bebas sebanyak 14 kali dan konveksi paksa 10 kali. Dengan kejadian yang didominasi adanya konveksi bebas ini, dapat menggambarkan bahwa faktor angin yang masih dominan adalah angin regional atau musiman seperti monsoon barat, mengingat saat penelitian ini adalah periode tanggal 1 sampai dengan 10 April 2019 di Stasiun Klimatologi Kelas I Bogor dan sekitarnya masih mengalami musim hujan. Proses konveksi paksa yang terjadi selama periode penelitian sebanyak 10 kali. Hal ini menggambarkan proses orografik di Stasiun Klimatologi Kelas I Bogor selama periode penelitian ini sekitar $33 \%$ kejadian.

Saat dihubungkan dengan kejadian hujan selama penelitian, ternyata saat kejadian hujan kondisi proses fisisnya bisa konveksi paksa, konveksi bebas, dan juga netral. Yang menarik perhatian adalah kejadian tanggal 3 April 2019, pada jam 13.00 terjadi proses fisis konveksi paksa dengan ditandai awan $\mathrm{Cu}$ sebanyak $\mathrm{n}=5$ dan 2 jam kemudian hujan sangat lebat dengan intensitas 106.6/jam dengan awan rendah CB sebanyak $n=6$. Dari 
catatan intensitas kejadian hujan, selama periode penelitian hujan yang terjadinya umumnya ringan.

\section{SIMPULAN}

Kestabilan atmosfer yang terjadi selama periode tanggal 1 sampai 10 april 2019 di Staklim Bogor, dapat dideteksi proses mikronya yang dapat menggambarkan proses konveksi. Nilai perhitungan Bilangan Richardson (Ri) pada periode tersebut berdasarkan 30 kali pengamatan untuk kondisi 1 menurut Stull (1988) kondisi 20 kali netral, 8 kali unstabil, dan 2 kali stabil. Sedangkan untuk kondisi 2, terjadi konveksi bebas 14 kali, konveksi paksa 10 kali, dan netral 6 kali. Selama 30 periode pengamatan terjadi hujan 9 kali kejadian dengan masa konveksi bebas 3 kali, konveksi paksa 3 kali, dan saat kejadian netral 1 kali. Hujan intensitas lebat mencapai 106.6/perjam terjadi saat konveksi paksa pada tanggal 3 April 2019 sekitar jam 15.00 waktu setempat.

Untuk dapat mencapai hasil yang lebih akurat, penelitian dapat dilakukan dengan data pengamatan yang lebih detail, misal pengamatan setiap jam, atau yang lebih kecil dari 1 jam, misal per 10 menit, atau 15 menit. Akan lebih baik jika ditambahkan nilai transfer momentum.

\section{DAFTAR PUSTAKA}

Alisawati.R.K, 2019. Skripsi Kajian Stabilitas Atmosfer Permukaan dan Pengaruhnya Terhadap Laju Transfer Momentum Pada Saat Kejadian Kabut di Wilayah Banjarbaru Pada Tahun 2018, Sekolah Tinggi Meteorologi Klimatologi Dan Geofisika,

Fujita T.T. 1981. Tornadoes and Downburst in the Context of Generalized Planetary Scales, Journal of the Atmospheric Sciences Volume 38 N0 8

Haidar.T.N, 2019. Skripsi Kajian Laju Transfer Momentum Terhadap Kondisi Stabilitas Udara permukaan sebelum Saat Dan setelah Hujan Di Kota Tangerang Selatan, Sekolah Tinggi Meteorologi Klimatologi Dan Geofisika, Oke TR.1978, Boundary Layer Climates, London: Methuen \& Co Ltd.

Orlanski. I. 1975. A Rational Subdivision of Scales for Atmospheric Processes, Bulletin of the American Meteorological Society Volume 56 No 5.

Stull RB. 1988. Meteorology for Scientists and Engineers. USA (US): Brooks/Cole Sutton. OG. 1953. Micrometeorology. New York (US): McGraw-Hill 
Sucahyono. D dan Ribudiaanto. K. 2013. Cuaca dan Iklim Ekstrim Di Indonesia, Pusat Penelitian dan Pengembangan Badan Meteorologi Klimatologi dan geofisika, Jakarta.

Suciatiningsih. F. 2013. Skripsi Karakteristik Kekasapan Permukaan Dan Pengaruhnya Terhadap Transfer Turbulen Momentum Dan Bahang, Departemen Geofisika Dan Meteorologi Fakultas Matematika Dan Ilmu Pengetahuan Alam Institut Pertanian Bogor

Wiryohamijoyo,S dan Swarinoto, Y.S 2013. Meteorologi Sinoptik : Analisis dan Penaksiran Cuaca Sinoptik. Pusat Penelitian dan Pengembangan Badan Meteorologi Klimatologi dan geofisika, Jakarta,

V.Tricio, J.F de Oliveira Junior, R.E, Viloria, G.B. Lyra Atmospheric Stability Conditions Based On The Richardson Number For the Region of Burgos, Spain. diakses https://www.academia.edu. 